\title{
Storm Spotting and Public Awareness since the First Tornado Forecasts of 1948
}

\author{
Charles A. Doswell III \\ NOAA/ERL/National Severe Storms Laboratory, Norman, Oklahoma \\ Alan R. Moller \\ NOAA/NWS Weather Forecast Office, Fort Worth, Texas \\ HAROLD E. BROOKS \\ NOAA/ERL/National Severe Storms Laboratory, Norman, Oklahoma
}

(Manuscript received 23 April 1998, in final form 1 October 1998)

\section{ABSTRACT}

\begin{abstract}
The history of storm spotting and public awareness of the tornado threat is reviewed. It is shown that a downward trend in fatalities apparently began after the famous "Tri-State" tornado of 1925. Storm spotting's history begins in World War II as an effort to protect the nation's military installations, but became a public service with the resumption of public tornado forecasting, pioneered in 1948 by the Air Force's Fawbush and Miller and begun in the public sector in 1952. The current spotter program, known generally as SKYWARN, is a civilian-based volunteer organization. Responsibility for spotter training has rested with the national forecasting services (originally, the Weather Bureau and now the National Weather Service). That training has evolved with (a) the proliferation of widespread film and (recently) video footage of severe storms; (b) growth in the scientific knowledge about tornadoes and tornadic storms, as well as a better understanding of how tornadoes produce damage; and (c) the inception and growth of scientific and hobbyist storm chasing.

The concept of an integrated warning system is presented in detail, and considered in light of past and present accomplishments and what needs to be done in the future to maintain the downward trend in fatalities. As the integrated warning system has evolved over its history, it has become clear that volunteer spotters and the public forecasting services need to be closely tied. Further, public information dissemination is a major factor in an integrated warning service; warnings and forecasts that do not reach the users and produce appropriate responses are not very valuable, even if they are accurate and timely. The history of the integration has been somewhat checkered, but compelling evidence of the overall efficacy of the watch-warning program can be found in the maintenance of the downward trend in annual fatalities that began in 1925.
\end{abstract}

\section{Introduction}

Although meteorologists readily acknowledge that their forecast products are not perfect, it is not always clear within the meteorological community how important public awareness can be in making forecasts successful in societal terms. It is natural that meteorologists focus on the meteorological aspects of the severe weather forecasting system; this is what meteorologists know best. Nevertheless, it is becoming ever more clear that public awareness is a major limiting factor in the success of severe weather forecasts, especially the very short range forecasts we call "warnings" for severe convective weather events such as tornadoes. The users

Corresponding author address: Dr. Charles A. Doswell III, NOAA/ National Severe Storms Laboratory, Norman, OK 73071.

E-mail: doswell@nssl.noaa.gov of weather forecasting information must hear the forecasts, must interpret them in their own terms in order to make decisions, and must know what to do in order to achieve some desired result, if the forecasts are to be successful in having a positive societal impact.

For severe convective weather (hereafter referred to as "severe weather") forecasts, most notably those associated with tornadoes, the recipients of the various forecast products [outlooks, watches, and warnings; see Ostby (1992)] must accept some level of responsibility for their own safety. Since the pioneering tornado forecasting efforts of United States Air Force meteorologists Ernest J. Fawbush and Robert C. Miller, the public has come to accept that the National Weather Service (hereafter, NWS) will provide forecasts and warnings to help the users to help themselves. Over time, the NWS also has accepted the responsibility for training severe weather spotters who volunteer to serve their communities by watching for imminent severe weather events, 


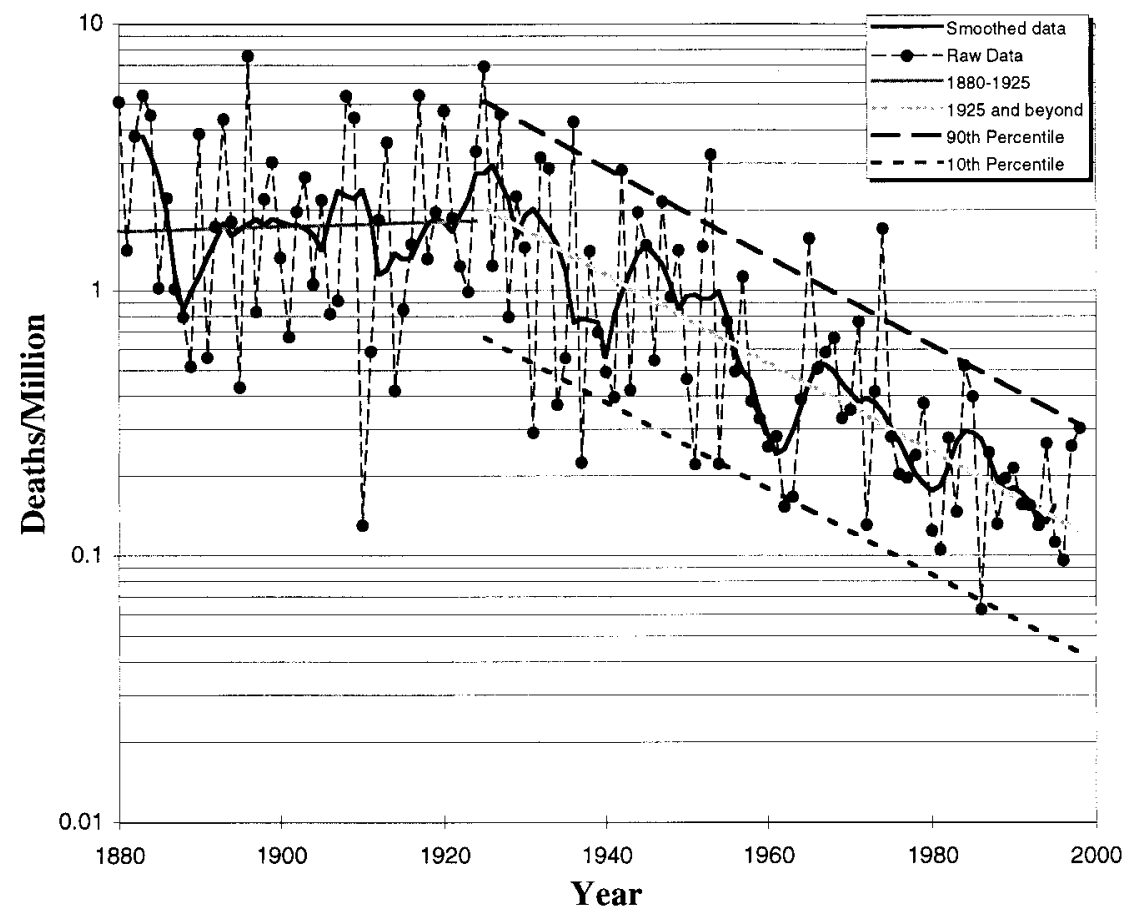

FIG. 1. Trends in the normalized annual tornado death toll, where the normalization is by the population of the United States for that year. The annual population has been estimated by linear interpolation between the census figures (at 10-yr intervals). The raw data (filled circles connected by dashed lines) were smoothed (thick solid line) by one pass of a three-point median filter, followed by one pass of a five-point simple moving average. The thick gray lines are the regression lines fitted to the filtered data for the period from 1880 to 1925 (dark gray), and for the period from 1925 to 1995 (light gray). The dashed lines are the 10th (short dashes) and 90th (long dashes) percentiles about the regression line for the period 1925-95.

again most notably tornadoes (but not limited to tornadoes). ${ }^{1}$ Finally, the NWS produces public information materials and makes them available for improving public knowledge of severe weather and what to do about it. All of these NWS activities have evolved in an effort to increase the likelihood that the forecast products will have the desired result of reducing severe weather-related casualties and damage.

As we review the history of the public awareness program since the inception of tornado forecasting in the late 1940s, we want to consider that history in a larger context. As shown in Fig. 1, the trend of the annual population-normalized death toll from tornadoes was nearly constant during the end of the nineteenth century and well into the first three decades of the twentieth century. It appears that something different began to happen after 1925. Although we can only speculate about the reasons for this change in the populationadjusted fatality rate, it seems likely that the deadly "Tri-State" tornado of 18 March 1925 made it clear to

\footnotetext{
${ }^{1}$ Note that volunteer spotters are quite distinct from the so-called cooperative observers who provide the National Weather Service with climatological observations. Some overlap might occur, but it is strictly coincidental.
}

the nation that spreading the word about a long-track tornado could have a positive impact on the populace in the storm's path. Radio and telephone communications technology proliferated during this decade, providing innovations that permitted rapid dissemination of warnings based on ongoing tornado events. Thus, it is possible that the Tri-State tornado initiated a trend toward public awareness that, combined with new communications technology, encouraged preparation for potentially disastrous tornadoes that continues to this very day.

It should be noted also that in the period from 1925 onward, there was a nationwide population movement away from rural areas and into cities (see López and Holle 1998). Thus, the population has become more and more clustered into large cities and the rural population, inherently more dispersed, has been declining. It is not known to what extent this may have influenced the trend shown in Fig. 1, but this demographic trend has two counteracting potential impacts. First, by clustering the population, it reduces the chances of a population center being hit. Second, on the relatively rare occasions when such a concentration of population is affected by a tornado, it increases the potential for casualties.

The important innovations of Fawbush and Miller and all of the subsequent public severe weather forecast 
product developments since the first tornado forecasts of the modern era can therefore be seen as contributions toward continuation of a trend that commenced more than two decades earlier in the wake of the Tri-State catastrophe. We will try to show that NWS efforts, past and present, to enhance public awareness have maintained a trend toward an exponential decrease in the normalized fatality rate. One of our goals will be to provide documentation of the training and preparedness materials created for the purpose of enhanced public awareness, as well as some overdue recognition of individuals who contributed to these public awareness efforts, and to the national program of volunteer storm spotters. It also will be shown that the effect of public tornado forecasting can be seen on the death tolls of major tornado events, but that success in reducing casualties from severe convective weather events cannot be used as an excuse to reduce the resources devoted to the task.

\section{History}

\section{a. Storm spotting}

As public awareness grew in the decades following the Tri-State tornado, it developed in a context wherein no efforts were being made to provide tornado forecasts. The earlier efforts of John Park Finley (Galway 1985) in tornado forecasting came to an abrupt end in 1886 (Galway 1989) and were not pursued further. Even the word "tornado" was banned from the Weather Bureau lexicon thereafter for many decade. In 1938, the word tornado was again approved officially for use with warnings, but not with forecasts (Bates 1962). With the recognition during World War II that defense installations and war production centers (like ammunition dumps and military supply depots) were quite vulnerable to thunderstorms and tornadoes, it is not surprising that the first efforts in organized spotting began in the military.

During 1942 and 1943, the Weather-Bureau cooperated with the military in setting up volunteer storm spotter networks in various places around the country where it was deemed important (Bates 1962; Galway 1992). At first, the primary concern was for lightning near ordnance plants, but the program grew substantially during the war and the mission of the spotters expanded to include other hazardous weather, including tornadoes, It is known that tornadoes had significant impacts on war production plants on 27 April 1942 in Pryor, Oklahoma (Grazulis 1993, p. 899), and damaged several buildings, including a barracks, at Fort Riley, Kansas, on 15 May 1943 (Grazulis 1993, p. 906). The year 1942 was notable for a substantial number of significant tornado events and those may have been influential in expanding the role of the military spotter networks. Undocumented near misses also might have contributed to the concerns of military authorities for tornadoes during the war. Galway (1992; see his Fig. 3) notes that by
June of 1945, there were more than 200 observer networks in place around the country. The origins of volunteer spotting probably predate this period, but the impetus for widespread encouragement and use of storm spotting is apparently a direct result of concerns on the part of the military during the war.

After World War II, the spotter networks were maintained, at least in part because of the continuing importance of military installations. After the catastrophic tornadoes of 9 April 1947 that tracked across parts of three states, ${ }^{2}$ the state of Texas began to put a special emphasis on volunteer spotters. A local spotter network was considered crucial in the issuance of warnings for a 1951 tornado near White Deer, Texas (Whitnah 1961, p. 216); another volunteer spotter group was noted to have been vital in triggering warnings during a tornado near Bryan, Texas, also in 1951 (Popkin 1967, p. 186). Following that, a major disaster at Waco, Texas, on 11 May 1953 stimulated the development of the Texas Radar Tornado Warning Network (AMS 1955). Although radar was a major component of this effort in Texas, wherein cities could buy surplus radars from the federal government for the price of installation and modification, the program also incorporated volunteer storm spotters. Apparently, the surplus radars never became a significant part of the system, but the spotters certainly did.

By the mid-1950s, spotters were well on their way to becoming commonplace, at least within the tornadoprone parts of the United States where terrain and visibilities permit them to be of use. ${ }^{3}$ This evolution followed rather directly in the wake of the inception of public tornado forecasts, permitting the alerting and deployment of spotters in advance of threatening weather situations. It is well known, of course, that the first tornado forecasts were issued by the U.S. Air Force forecasters Ernest C. Fawbush and Robert C. Miller on 25 March 1948, from Tinker Air Force Base. By March of 1952, the United States Weather Bureau had initiated its own public severe storm forecasting service, known as the Severe Local Storms Forecasting Unit [abbreviated as SELS; see Galway (1989); Corfidi (1999)], first in Washington, D.C.; this forecasting group moved to Kansas City, Missouri, in August $1954 .^{4}$ Although

\footnotetext{
2 This event was described as another "tri-state" tornado by Lynch (1970). Doswell and Burgess (1988) have indicated that it most likely was a family of tornadoes rather than a single, long-track tornado. The event left devastation in its track across the Texas panhandle, northwestern Oklahoma (including the city of Woodward), and southwestern Kansas.

${ }^{3}$ To this day, spotters have difficulties in the eastern third of the nation, because low clouds, haze, vegetation, complex terrain, and human construction all act to limit the visibility of tornadoes. Nevertheless, considerable effort is still being put into development of spotter programs across the nation.

${ }^{4}$ This group has been moved again, this time to be collocated with the National Severe Storms Laboratory, in Norman, Oklahoma.
} 


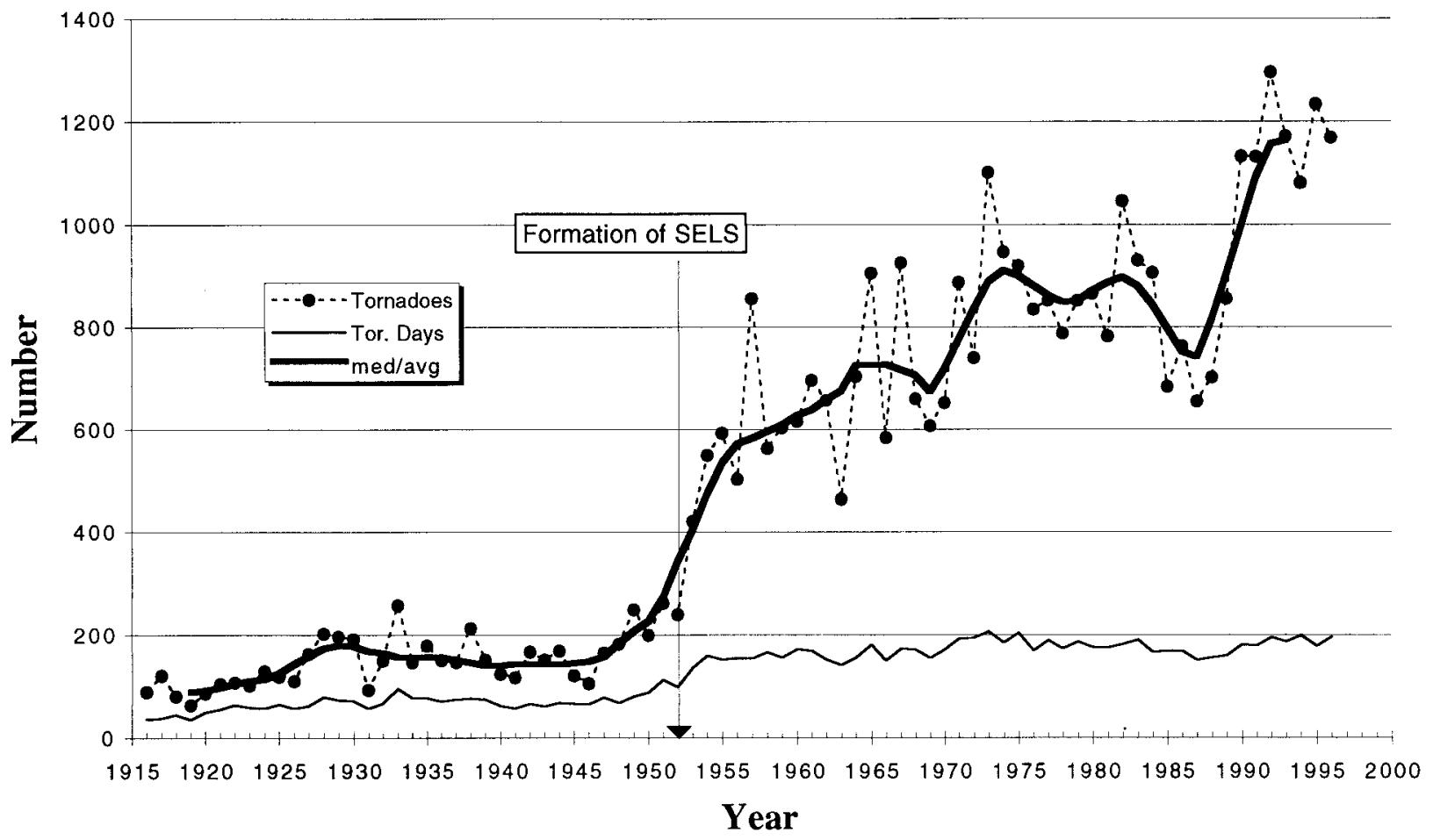

FIG. 2. Annual number of tornadoes for the period 1916-95; the dashed line connecting solid circles shows the raw data, the heavy solid line is the result of smoothing (using the same method as described in Fig. 1 caption). Also shown in the light solid line is the number of tornado days (i.e., days with one or more tornadoes) per year. The formation of SELS is indicated.

SELS has not taken a direct hand in recruiting spotters or even promoting their use, its products permit the timely deployment of spotters. Thus, it certainly can be said that public tornado watches have been a major impetus to the spotting program; it is also apparent that the deployment of spotters promotes the detection of tornadoes. The record of the number of tornadoes observed (Fig. 2) shows clearly the impact of the proliferation of spotter programs in the era following the formation of SELS (see Galway 1992).

Another watershed event was the Palm Sunday outbreak of tornadoes of 11 April 1965. Although the SELS tornado watches were reasonably accurate for that event and there were at least some local warnings (often with the help of volunteer spotters), the findings of the Weather Bureau Survey Team (1965) led by Paul H. Kutschenreuter ${ }^{5}$ made it quite clear that the dissemination of the meteorological information was less than adequate and that the public was poorly prepared to use the information if and when they received it. Among

\footnotetext{
${ }^{5}$ Other team members included Roy Fox (regional director, Weather Bureau Central Region), Dr. Edwin Kessler (director, National Severe Storms Laboratory), Allen D. Pearson (then head of the Emergency Warnings Branch, Weather Bureau Headquarters, soon thereafter to be appointed the director of the National Severe Storms Forecast Center), and Herbert Lieb (acting director, Public Information Office, Weather Bureau Headquarters).
}

other things, this led to the formation of the Natural Disaster Warning system (NADWARN) to coordinate the various federal agencies (the participating agencies and their names have changed regularly) that have natural disaster-related emergency functions. NADWARN soon included a tornado-specific plan that we know now as SKYWARN. Also in association with the post-Palm Sunday era, the tornado "forecasts" officially became tornado "watches" in 1966 (Galway 1989).

With the development of SKYWARN, the spotters have had a structure within which they operate in collaboration with the NWS. It is beyond the scope of this review to evaluate the effectiveness of the program as a whole, but the overall efforts have been important in the reduction of fatalities from major tornadoes. For example, no single tornado since 1953 has resulted in 100 or more fatalities; the last such event was the Flint, Michigan, tornado of 8 June 1953, that killed 114 people. Note that communications technology, notably telephone and radio, has been an important component of the spotter network. Spotters have to get their information to their communities; this aspect of the program will be discussed in section 3 .

\section{b. Spotter training programs}

It was recognized early on that if volunteers are to provide useful information about approaching storms to 
their communities (and through the local emergency managers to the NWS), the spotters need training. The Weather Bureau (now known as the NWS) readily accepted a key role in the development of such training materials and has always been ready to provide such training when asked. The history of these training materials has not been well documented in the past. Many individuals, in and out of government, have contributed to the creation of training films-videos, slide programs, and pamphlets and especially with respect to the earliest of these, in the 1950s and 1960s, we have relatively little information about who was involved. Apparently, the labors associated with producing these in the era from the late 1950s to the early 1970s were considered simply part of someone's job and relatively few of those involved have ever received any public recognition, unfortunately.

The following represents an abbreviated review of the materials that have been produced for spotter program training. We cannot claim this list to be complete or exhaustive, but it does provide some sense of the timing and content of spotter-related training material. The listings also identify, to the best of our current ability, those who have contributed, in an effort to provide individual credit where it is due. We begin with spotter training films and videos; we may have missed some examples. We find that most of the information from the late 1950s through the early 1970s about who was responsible for the development of these films is not readily available.

1) Tornado (1956): A “Calvin Production" sponsored by United Gas Corp. and Texas Eastern Transmission Corp., set in the fictitious town of Elmville, Oklahoma. It showed a volunteer spotter who phones in a tornado report to the local Weather Bureau office. A News and Notes entry in the Bulletin of the American Meteorological Society (AMS 1957a, p. $300)$ points out that the sponsors of this film received a Public Service Citation from the Weather Bureau, and that Berne P. Hughes (then the meteorologist in charge at Shreveport, Louisiana) is "cited for his excellent technical assistance during the development and production of the tornado film," receiving a Superior Accomplishment Award. Mr. Hughes also is noted as being responsible for presenting the idea for the film to the eventual sponsors. The Bulletin of the American Meteorological Society (AMS 1957b) notes later that Harry E. Altman also received a Superior Accomplishment Award "in recognition of his work leading to the production" of the film.

2) Tornado! (1968): Produced for the Weather Bureau by Astra Films Inc., with Jeff Baker noted as the executive producer, Leonard Grossman noted as the producer, and including Northern Natural Gas Corp. among those acknowledged. It made the distinction between watches (for planning) and warnings (for action). It premiered at the Smithsonian Museum in
January of 1968. As of this writing, we have no information about any individuals who may have made important contributions during the production of this film.

3) Twister (1972): Produced by the NWS in cooperation with the Defense Civil Preparedness Agency (hereafter, DCPA). It focused on the 11 May 1970 Lubbock, Texas, tornado disaster. As of this writing, we have no information about any individuals who may have made important contributions during the production of this film.

4) Day of the Killer Tornadoes (ca. 1975): Produced mostly by the DCPA, highlighting the 3-4 April 1974 "Super Outbreak," depicting honestly the local situations in Brandenburg, Kentucky; Xenia, Ohio; Cincinnati, Ohio; Louisville, Kentucky; and Huntsville, Alabama. The first two had little preparedness and no sirens, the last three had excellent disaster plans and sirens, and the film points out the differences in community death tolls. As of this writing, we have no information about any individuals who may have made important contributions during the production of this film.

5) Neosho (ca. 1976): Produced by the NWS (with significant support, including assistance with the funding, from Herb Lieb) provided an example of what could be done by communities. It focused on the 24 April 1975 tornado in Neosho, Missouri. The DCPA may have been involved, as well. As of this writing, we have no more information about individual or groups who may have made important contributions during the production of this film.

6) Tornado-A Spotter's Guide (1977): Produced by Mike and Betty Durham and Dan Purcell for the NWS, with input from Les Lemon, Chuck Doswell, and Al Moller. This film was produced to update storm spotting, based on what storm intercept efforts had learned since 1972; it also was the basis for developing a new spotter training slide series (see below). It featured an emphasis on what storms look like before they produce tornadoes, noting the significance of the rotating wall cloud. It became the top-selling U.S. government film ever in peacetime.

7) Terrible Tuesday (1984): Produced by the NWS, focusing on the 10 April 1979 major tornado event in Wichita Falls, Texas. It emphasized the importance of preparedness, spotter training, etc. As of this writing, we have no information about any individuals who may have made important contributions during the production of this film.

8) Stormwatch (1995): Coproduced for the NWS by Martin Lisius of Prairie Pictures, Inc.; Al Moller; and Gary Woodall. This represents an advanced spotter training video, providing more advanced aspects of storm structure and emphasizing the differences between wall clouds that are likely to become tornadic versus those that are not. 


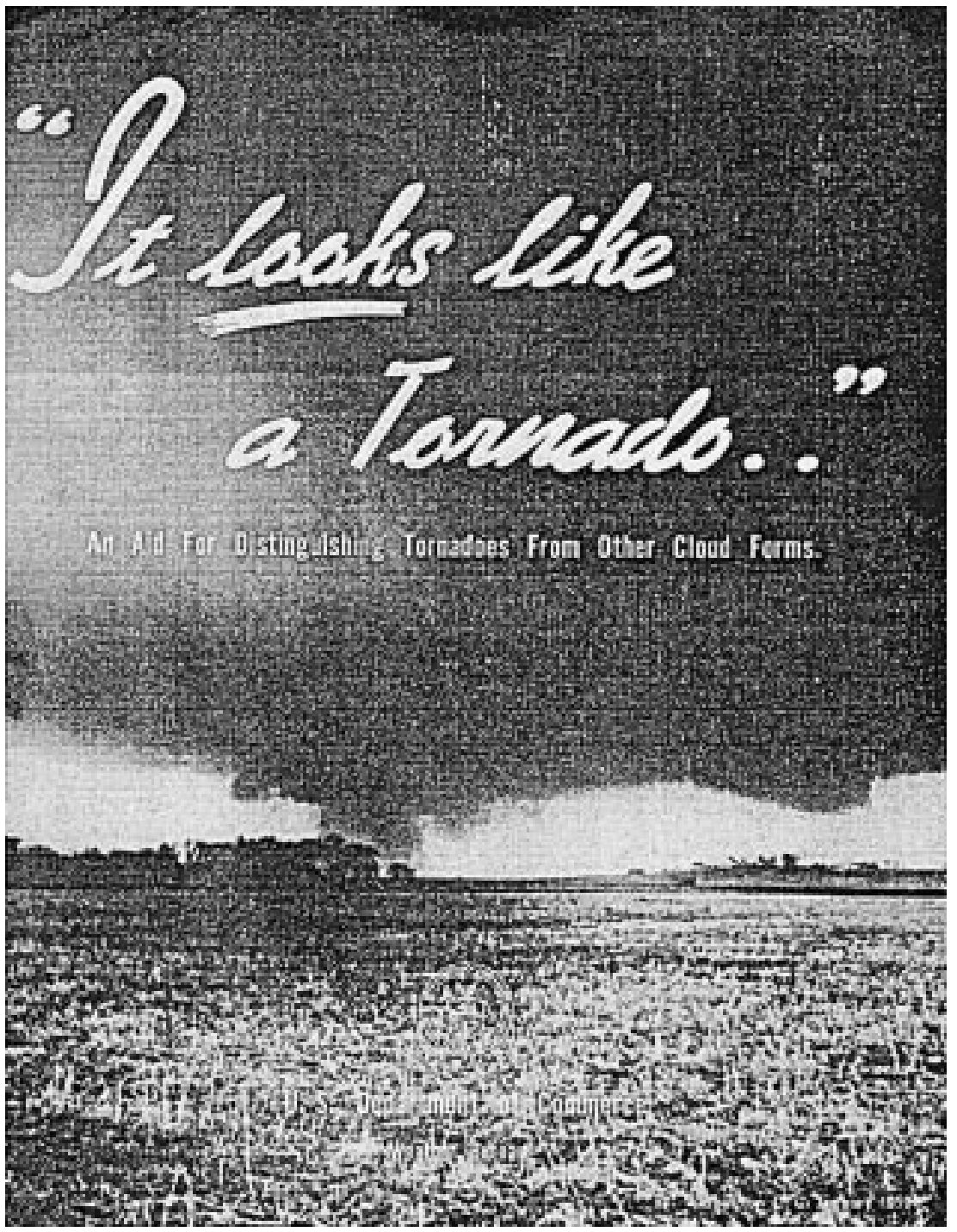

FIG. 3. Cover of the 1959 Weather Bureau pamphlet entitled "It looks like a Tornado."

The various Weather Bureau/NWS slide sets, pamphlets, and brochures for spotter training are revised at irregular intervals. The budget for these items is quite modest and subject to reduction in times of fiscal distress. Most recent revisions have been done on quite small budgets and with very limited financial resources; a lot of time and effort has been contributed without charge by concerned individuals both in and out of government. As with the films and videos, we make no pretense of having a comprehensive listing here, but the following list is at least broadly representative. As of this writing, we are mostly unaware of by whom and under what auspices training brochures and manuals were created prior to the mid-1970s.

1) "Severe Storm Reporting Handbook" (1956): This document provided information about how to go about reporting severe weather, including torna- does, to the "collection agency" associated with a volunteer observing network. It described how to recognize a tornado and included a few photographs, and even some safety rules.

2) "It looks like a Tornado" (1959): This document (Fig. 3) stated that it is an "Official Weather Bureau handbook for use by tornado network observers" and included photographs of tornado look-alikes, as well as variations on tornadoes.

3) Severe Local Storms-Spotter Training Slide Lecture Series (1969): This program apparently was produced by Weather Service Headquarters in response to requests from field offices for updates to the Storm Reporting Handbook.

4) "Spotter's Guide for Identifying and Reporting Severe Local Storms" (1970): A pamphlet that provided meteorological information about hazards as- 
sociated with thunderstorms; information about tornadoes, in particular, an example of the life cycle of a tornado (near Freeman, South Dakota, on 1 June 1965; an example much used in later revisions of tornado pamphlets of all sorts); tornado lookalikes; and reporting procedures.

5) Tornado Preparedness (1976): Weather Service Headquarters produced this slide set.

6) The Safest Place in Schools (1976): A slide program developed by Prof. James Abernathy of the Lawrence Institute of Technology in Southfield, Michigan. This program was prepared after several schools were struck during the 3-4 April 1974 tornado outbreak.

7) Tornado Safety in Residences (ca. 1978): Another slide program developed by Prof. Abernathy.

8) A Slide Series Supplement to "Tornado-A Spotter's Guide” Slide Set (1978): Designed to accompany the film Tornado-A Spotter's Guide during spotter training sessions, this program was the first revision of the spotter training material based on storm chasing experiences. Les Lemon was the leader in development of this set, which provides comprehensive storm structure information for spotters for the first time. Chuck Doswell developed most of the schematics used in the series, provided input, and contributed images for use in the series. Al Moller also provided input and images; many storm chasers, notably including David Hoadley, contributed images for use in this slide program.

9) "Spotter's Guide" (1981): A pamphlet created as a revision to the earlier pamphlet, as an additional supplement to the film Tornado-A Spotter's Guide. This incorporated the new information about storm spotting that began with the 1979 film, providing some of the same schematic storm structure diagrams developed for the slide series. It also showed sequences of tornadoes starting from before the tornado and illustrating wall cloud formation, provided examples of tornado look-alikes, gave information about spotting procedures, and presented a glossary of storm-related terminology. Larry Mooney was instrumental in producing this document, with input from Al Moller and Chuck Doswell.

10) A Look at Thunderstorms and their Severe Weather Potential (1988): Subtitled "An Advanced Severe Storm Spotter Training Slide Series," the leader of this program was Al Moller, who also contributed images and guided the content, with input (including designing new schematics) and images from Chuck Doswell, and with photo contributions from several other storm chasers. NWS Southern Region Headquarters provided considerable support for the development of the series. Joan Kimpel of the National Severe Storms Laboratory created the finalized graphics, and a presentation of the concept of the series (Moller and Doswell 1988) won the "Best
Graphics" award at the 1988 American Meteorological Society's 15th Conference on Severe Local Storms held in Baltimore, Maryland.

11) “Advanced Spotter's Field Guide (1992): This guide provided updated meteorological information about severe thunderstorms, supplementing the $A d$ vanced Spotter's Guide slide program. Gary Woodall supervised the development of the guide, while Al Moller and Chuck Doswell provided input. Many chasers contributed images for this set.

12) Concepts of Severe Storm Spotting (1996): Subtitled "A Basic/Intermediate Spotter Training Program," this was developed primarily by Gary Woodall, with input from Al Moller and Greg Stumpf, and benefited from production assistance contributed by Bill Alexander and Linda Kremkau in NWS Headquarters. As is the norm now, many storm chasers contributed images for this slide program. This was an update of the earlier basic spotter training slide set introduced in 1978.

\section{c. Public awareness programs}

The following materials (films, pamphlets, etc.) are aimed at the public, rather than spotters, attempting to raise public awareness of tornadoes and what to do in case people experience threatening weather situations. It has become clear that as the meteorological science and wind-engineering knowledge associated with severe local storms (especially, tornadoes) grows, topics that we thought we understood are revised and so our recommendations about actions have to change. Public education efforts are a major task, and having to "unteach" something can be frustrating and is almost never $100 \%$ effective. Making changes to the safety rules, for example, has proven to be maddeningly difficult. Myths about tornadoes survive, including myths that once were ideas on the frontiers of our science (see, e.g., Reynolds 1958). That is, the changing science turns our apparently scientific facts into mythology as we learn more. There does not seem to be any way around the fact that our science is going to change and that we thereby will be forced to change the messages we give to the public. However, this probably argues for a moderately conservative viewpoint regarding changes to our public pamphlets and other materials.

As we have noted, public awareness appears to have been a major factor in the exponential decrease in per capita tornado fatality rates. Although the NWS has been reasonably conscientious in developing revised tornado spotting training as new things are learned, it perhaps can be said that we are much less involved in developing programs aimed at educating the public at large about our changing science of severe local storms than we are in developing new spotter training materials. Given that public awareness appears to have been a major factor, if not the major factor, in declining tornado death tolls, it seems inappropriate not to be putting a 


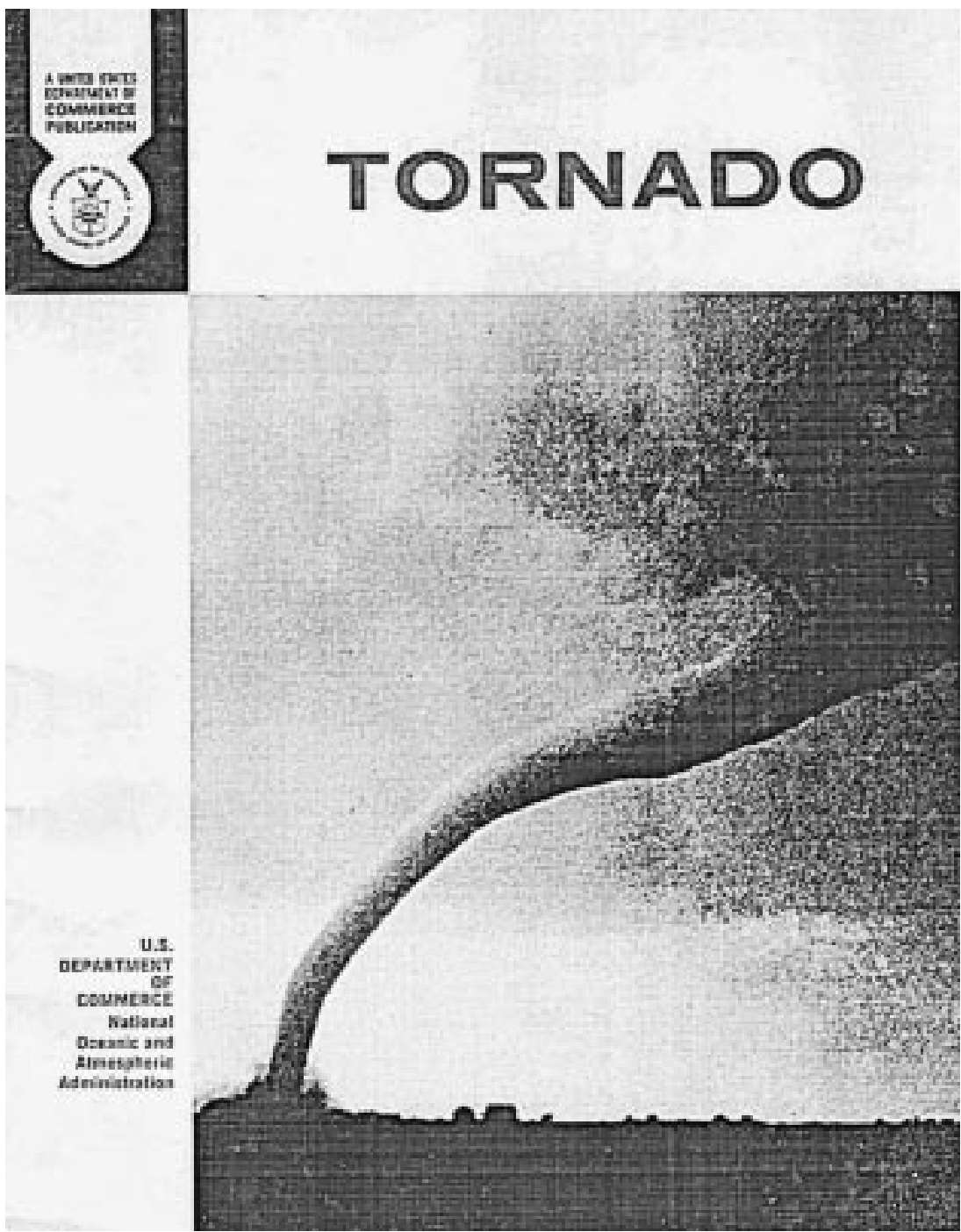

FIG. 4. Cover of the 1970 National Weather Service pamphlet entitled "Tornado."

significant emphasis on this aspect of an integrated warning system. What follows is a short history of documents intended for public use.

1) "Tornadoes-what they are and what to do about them" (1960): This was a short (four page) NWS pamphlet giving some brief summaries of climatological and meteorological information that was apparently aimed at the public.

2) “Tornado Watch" (1965): This small NWS pamphlet described what a tornado watch is and uses as an example the watches issued for the Palm Sunday outbreak of 11 April 1965.

3) "Tornadoes" (1965): This was a series of pamphlets from the NWS that provided summaries of climatological and meteorological information about tornadoes for the public, including tornado safety information, preparedness planning, and information about other thunderstorm-related hazards. It was is- sued annually, often with "facelifts" of various sorts, including being renamed "Tornado" by 1967. In its 1965 and 1966 incarnations, it even provided instructions for building a personal "tornado cellar." The 1970 version (Fig. 4) featured the Tracy, Minnesota, killer tornado of 13 June 1968 (rated an F5) on its cover.

4) Tornado-Approaching the Unapproachable (1972): Produced by Tom Grazulis of Environmental Films, Inc. This film showed several clips of tornadoes, including the infamous 2 April 1957 event in Dallas, Texas. It was quite popular, having been shown on television many times.

5) "Tornado Safety—Surviving Nature's Most Violent Storms" (1982): This NWS pamphlet was another update of public awareness materials, explaining watches and warnings, giving safety rules, and showing updated tornado climatological information from 
work by Don Kelly, Joe Schaefer, Chuck Doswell, Bob Abbey, and Rich McNulty. Joe Galway contributed maps of six of the nation's worst tornado outbreaks.

6) "Tornadoes ... Nature's Most Violent Storms" (1992): This was an updated version of earlier public information pamphlets, produced by a collaboration among the NWS, the Federal Emergency Management Agency, and the American Red Cross. It is one of a pamphlet series that covers other hazardous weather events (e.g., floods, winter storms, hurricanes, etc.) besides tornadoes. Notable among the items within this pamphlet are some "tornado myths" that include an attempt to change the safety rule about opening windows to alleviate pressure drops associated with the tornado that at one time were believed important in causing buildings to "explode." As with other, older tornado safety rules, this one has been known for some time to be erroneous and possibly dangerous.

\section{An integrated warning system}

Spotters are just one component of an integrated warning system. An integrated warning system (hereafter, IWS) consists of the four basic elements: forecast, detection, dissemination, and public response (Leik et al. 1981). As noted in Moller et al. (1993), there are three primary groups of users of weather information in an IWS: 1) news media and private sector meteorologists, 2) emergency management officials and storm spotters, and 3) the general public. The latter group, the general public, is difficult to characterize in terms of its needs and interests, since "the public" is not a monolithic group with a single set of requirements. Perhaps the first two groups are not homogeneous either, but there certainly are some common threads within them.

It already has been noted that even if meteorologists could produce forecasts that are perfectly precise and accurate, when the other parts of the IWS break down for some reason, those forecasts do not achieve fully their purpose of reducing casualties and damage (see Perry and Mushkatel 1984, chapter 2). The historical information we have provided makes it quite clear that public awareness and preparation can make a large difference in the outcome of a given meteorological event.

The NWS has direct contact with the public only through the somewhat limited medium of the NOAA Weather Radio (see below); the majority of its information concerning hazardous weather reaches the users of that information by means of the media, private sector meteorologists, and emergency managers. Although this arrangement works reasonably well across the nation, there are a few places where the relationship among the groups has not always been as cordial and mutually supportive as it needs to be. Moreover, the various disseminators of weather information are not always on the best of terms with each other. Competition for mar- ket share can become a negative factor within an IWS. Even emergency managers (hereafter, EMs) and spotter groups within a community can at times be troubled by internal problems that can interfere with effective dissemination of weather information to the users. However, we want to emphasize that most of the time and in most locations, the arrangement operates satisfactorily because all the participants are supportive of a true integration of the components. A truly integrated warning results whenever and wherever the local participants choose to suppress their internal conflicts (if any) for the greater good of public service.

The NWS has certain key roles (forecasts and warnings, meteorological aspects of storm spotter training), but the vital jobs of dissemination and community protection are in the hands of the media and the EMs. Let us review briefly how things would work in an ideal world.

The IWS process actually can be said to begin well before any severe weather has even begun to loom on the horizon. Local communities, including the citizens as well as public officials within them, have to accept a primary responsibility for preparing their communities to deal with what is a relatively rare phenomenon. The tasks associated with this responsibility include development and implementation of a disaster emergency plan, initiation of contact with the NWS and other agencies of federal and state government to coordinate the planning and spotter training sessions, and the identification of participants in a storm spotting network. There must be some sort of Emergency Operations Center (hereafter, EOC) set up that can coordinate all aspects of the program within that local community during an event, including communication with the NWS, other disaster agencies, and within the local community.

From that point, the NWS is invited to put on storm spotter training programs at the request of the local EMs. ${ }^{6}$ The needs of the communities can vary, depending on the experience level of their spotters. The offering of advanced spotter programs, beyond the basic material presented to new spotters, is contingent on the experience level of the local spotters. Some programs have very enthusiastic and innovative leaders, who can broaden the range of speakers available by bringing in outside expertise to supplement the training provided by the local NWS. Nevertheless, the most basic and important part of the spotter training program is to work with the local NWS staff. Experts from outside will be long gone when severe weather threatens the community and the spotter training meeting provides an ideal forum for everyone in the IWS to get to know each other.

In the ideal world, there should be feedback between the spotters and the people doing the spotter training.

\footnotetext{
${ }^{6}$ The NWS must be invited formally to perform this task, but local offices certainly do their best to encourage communities to extend the invitation.
} 
No one who has observed severe storms can say legitimately they have seen it all; the processes that produce severe local storms are not perfectly understood and even research scientists and chasers who have been observing storms for more than 20 years still experience things they have not seen before. If a spotter is confused by something that he or she sees, there should be an opportunity to share that with the NWS spotter trainers, so that the training program can address those questions, if possible. Although some local efforts to develop this feedback are under way, there is as yet no organized, systemwide attempt to promote it.

Assuming that the development of the infrastructure of a volunteer storm observing network is done and that the training of the spotters has been carried out, then the system maintains vigilance until a threatening weather situation arises. Most spotters are volunteers who have other responsibilities and they simply cannot afford to be idle, waiting for a threatening storm. Thus, the NWS forecasters take on the task of alerting communities to the immediate threat of severe local storms, allowing the spotters to go about their normal tasks until they are needed. A potential deployment of spotters begins with an "outlook" of severe weather, issued by the Storm Prediction Center (SPC), ${ }^{7}$ perhaps as many as two days prior to the anticipated hazardous weather event. The outlook is designed to provide a long-range look at the possibilities, but it typically covers broad areas with its intent being to help NWS offices and other components of the IWS be prepared to provide emergency staffing as threatening weather develops.

As the day of the severe weather threat opens, the local NWS office can choose to issue an outlook of their own for that day, with the idea being to put EMs on the alert to the possible need for spotter activation. Not all offices provide this sort of product; it is described in more detail in Moller et al. (1993) and Moller et al. (1994).

When it becomes apparent that the threat of severe local storms can be localized, it currently is the duty of the $\mathrm{SPC}^{8}$ to issue tornado and severe thunderstorm watches. Watches are areas of roughly $25000 \mathrm{~km}^{2}$ (roughly, $10000 \mathrm{mi}^{2}$ ) in which the threat of severe local storms is thought by the forecasters in the SPC to be relatively high. The watch is designed to alert both the public and EMs; the latter need to be alerted in order to give them time to deploy storm spotters. Following watch issuance, if the threat materializes to the extent that it either is observed or is seen on radar to be im-

\footnotetext{
${ }^{7}$ See Ostby (1992) for a discussion of National Severe Storms Forecast Center (NSSFC) operations; the NSSFC has become the SPC.

${ }^{8}$ In the future, the watch responsibility may be transferred to the local offices, as part of the modernization and restructuring of the NWS.
}

minent, the local NWS offices issue warnings that cover counties or parts of counties.

Still in this ideal world, the spotters are deployed within watch areas and they report to their EOCs when they see reportable severe weather events (primarily hail, strong winds, and tornadoes, but also heavy rainfall and flash floods). In fact, the spotters may have made the initial observation that resulted in a warning by the NWS. Alternatively, if the NWS warning was initiated on radar evidence just prior to the development of hazardous weather, the spotters can provide feedback to the NWS about the weather they see, via their EOCs. When spotters observe a severe weather event that is definitely threatening their community, they report this directly to their EOC, and the EM makes whatever decisions are necessary to initiate life- and property-saving actions (such as turning on tornado sirens, if they exist) in their community. This information is passed on to the NWS, as well, which may influence forecaster expectations for areas downstream from the current threatening storms. That is, the reports can prompt further warnings from the NWS, as long as the storms remain threatening.

Given the perishable nature of information about severe weather, there is a premium on getting this information out quickly; media outlets can choose to break in on their programming to get warnings on the air as soon as possible. Not all the media choose to approach this with the same level of commitment, and the nature of the specific programming often influences this decision. In lieu of breaking in, television stations often use "crawls" and only break in during truly critical situations. It is rare when advertising segments of a broadcast are interrupted to disseminate warning information.

A recent development is the popularity of cable and direct satellite feeds of television programming. It is possible to have the local cable company provide warning "crawls" if the community has requested that service in their contract with the cable company. For direct satellite feeds, especially widespread in rural areas, it is difficult to envision how that might carry local weather warning information.

Another dissemination medium is via the so-called NOAA Weather Radio (NWR), which is programmed directly by the NWS. The "reach" of NWR is sharply limited by the number of transmitters, since the broadcasts reach only to locations within the transmitter's line of sight. There have been some efforts to upgrade this service in recent years, notably after the killer tornadoes in Alabama on 28 March 1994, by increasing the number of transmitters. Although NWR is broadcast freely, a special radio must be purchased to receive it, as it does not use the regular AM/FM radio broadcast bands.

There also is a National Warning System (NAWAS) that connects NWS offices with other federal and state agencies around the country. NAWAS is a party-linetype telephone system that exists within the Federal Emergency Management Agency (FEMA). There are 10 
regional circuits that can be bridged to form a nationwide capability, if needed. Its main role is to facilitate coordination in emergencies and has no "routine" traffic. NAWAS initially was developed as a response to requirements of the Federal Civil Defense Act of 1950, to provide warnings of an imminent military attack on the nation, but has never been used for that purpose.

Considerable communication among spotters, EMs, and the NWS is done via amateur radio. This normally falls under the aegis of SKYWARN, which attempts to integrate various amateur radio groups as well as other components of the IWS. To some extent, telephones still carry some of the burden for disseminating hazardous weather information, especially in rural areas.

It has been shown that a significant barrier to getting people to take action is when the information about warnings that reaches them includes conflicting guidance. Thus, the NWS generally is designated to be the primary decision maker about the need for warnings. This policy is not followed uniformly and differences of opinion between the media and the local NWS offices about this issue, or about interpretation of weather data, can be a problem in the smooth operation of an IWS. Generally speaking, however, in most locations, the NWS is recognized as the primary source for severe weather warnings.

The real world of hazardous weather is sometimes rather far from ideal. The sequence of forecast products is not always the simple, somewhat linear process we have just described. Sometimes tornadoes occur in severe thunderstorm watches. Sometimes severe weather warnings precede the issuance of watches. Sometimes the outlooks need to be amended when unanticipated severe local storms develop. Sometimes local EMs get panicky and trigger sirens in situations that do not warrant such actions. Not only is the meteorological side of the IWS filled with uncertainty, but the nonmeteorological component in an IWS operates at a level short of perfection.

It is important not to engage in "finger-pointing" exercises when things in an IWS go wrong. Although it is undoubtedly appropriate to assess the performance of all the components within an IWS after a severe weather event, all components in an IWS need to accept that they are responsible collectively for its performance. When things go wrong, the important thing to do is to try to fix those flaws to whatever extent it is possible, rather than to spend time trying to establish who is to blame. If integration of the components is an agreedupon goal, it seems pointless and particularly counterproductive to spend time trying to blame someone, which can only create ill-will and engender defensive reactions that are a barrier to effective integration.

\section{Discussion and conclusions}

The historical record of tornado fatalities (Fig. 1) might be used to infer that much of the decrease in fatalities can be attributed to simple public awareness, and that the effect of public forecasting service programs does not appear. After all, the downward trend began after the famous Tri-State tornado of 1925, long before any public tornado forecasting began. ${ }^{9}$ However, we believe this would be a misreading of that record. It is impossible to know what that record might look like had we not instituted public tornado forecasting, but it is plausible to suggest that the trend shown could have leveled off at a higher fatality rate than at present. It seems likely that maintaining that downward trend must be attributable to some extent to programs like the development of spotter programs, the inception of public tornado forecasting, and the public awareness efforts that have been undertaken by the members of the IWS (i.e., the NWS, the media, schools, etc.). Thus, we believe that what has been important has been the efforts to continue to build public awareness.

In support of this contention, Fig. 5 shows the apparent impact of the inauguration of public tornado forecasts and the ensuing program of watches and warnings, combined with public education and disaster planning. The trend of the ratio of dollar damage to fatalities changes abruptly in the period following the inception of public tornado forecasting. The rapid, organized development of an infrastructure for dealing with tornadoes also begins with public tornado forecasting in 1952. The major tornado events shown in Fig. 5 were selected by first finding all tornadoes causing 46 or more fatalities, then finding all tornadoes that produced at least \$50 000 worth of damage (in inflation-adjusted 1997 dollars). ${ }^{10}$ After combining these and eliminating duplicates, each tornado's "impact" was estimated by combining its inflation-adjusted damage with a figure representing each fatality as equivalent to $\$ 8$ million. ${ }^{11}$ The set of events was ranked according to this measure and the number of events selected was truncated at the arbitrary figure of 109 tornadoes out of this ranked listing. In the figure, the tornado at Flint, Michigan, on 8 June 1953 has been chosen somewhat arbitrarily as the separator between the two regression lines, since it is the last single tornado to cause 100 or more fatalities in the United States. The trend lines are simply regression lines fit to the data, showing the apparent discontinuity that coincides roughly with the inauguration of public tornado forecasting.

We have estimated that if the trend in period leading up to and including the Flint event had remained unchanged, then more than 13000 additional fatalities

\footnotetext{
${ }^{9}$ As already noted, to some unknown extent, this trend has been influenced by changing demographics.

${ }^{10}$ Obviously, these numbers are essentially arbitrary.

${ }^{11}$ This figure is taken from the Web site presentation of Molly K. McCauley (http://www.dir.ucar.edu/esig/socasp/weather1/macauley.html) who states therein that "Numerous studies suggest that the value of a statistical life is around $\$ 8$ million...."
} 


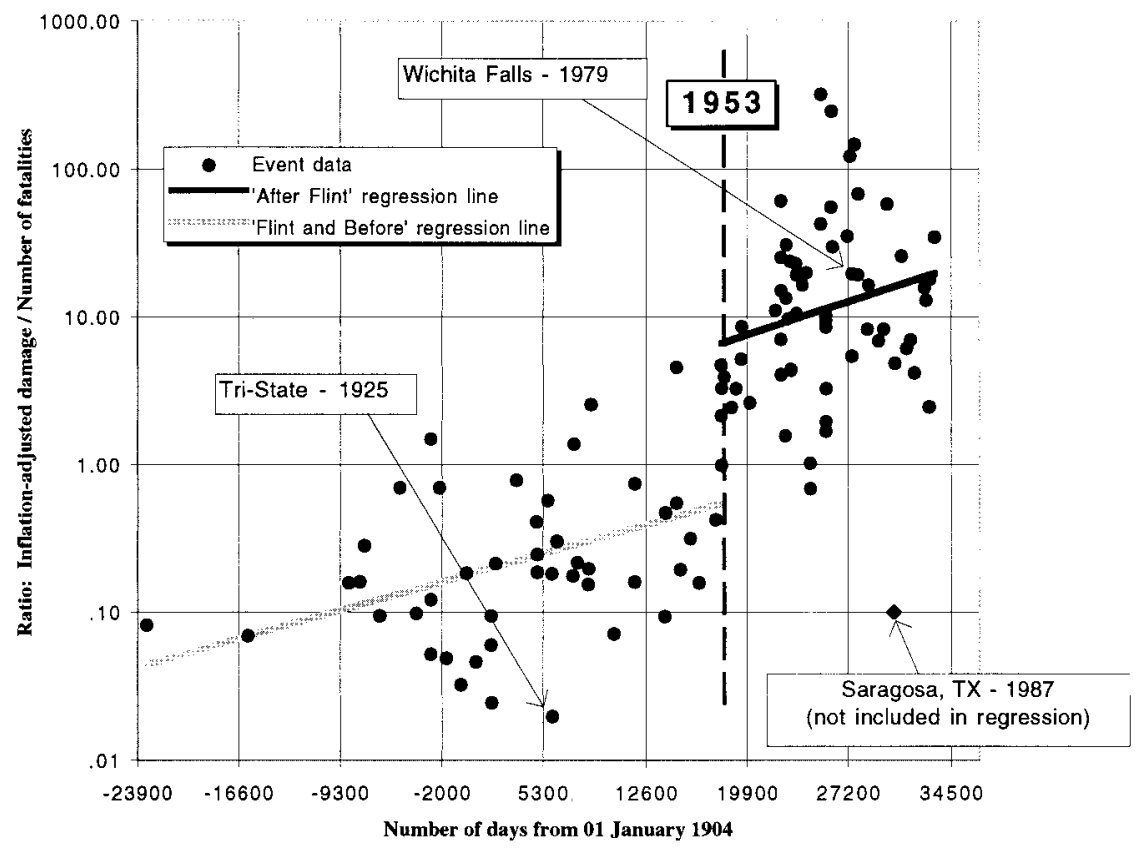

FIG. 5. Trends in the ratio of the damage to the fatalities, for selected tornado events in the period from 1880 to 1995 . Events were selected by a procedure described in the text. The abscissa is the number of days from 1 Jan 1904 and the ordinate is the ratio of the inflation-adjusted damage (in 1997 dollars) to the number of fatalities. The solid black circles are the individual events; the thick gray line is the fitted regression line for events during the period up to and including the Flint, MI, tornado on 8 Jun 1953; the thick solid line is the regression line for events after the Flint event. The 1987 Saragosa, TX, event is shown by a filled diamond.

might have occurred with the events shown in the figure. For example, the Wichita Falls, Texas, tornado of 10 April 1979 potentially could have killed 630 persons instead of the actual 45 fatalities, if fatality rates associated with that amount of damage had not changed around 1953. This value is only speculative, of course, and should not be taken too literally. However, a rough estimate on the order of 10000 lives spared as a result of the steps taken in the wake of the pioneering efforts of Fawbush and Miller in 1948 may not be unreasonable. ${ }^{12}$

The Saragosa tornado of 22 May 1987 is indicated in the figure, even though it is not included in the regression because it failed to meet the aforementioned criteria (the number of fatalities was too low to qualify). In the case of this event, a violent tornado struck a poor, rural community that had virtually no preparedness program, in part because it was unincorporated. In spite of excellent NWS warnings (triggered in part by timely and accurate spotter reports) in advance of the tornado (see NWS 1988), the damage/fatalities ratio seems to resemble an event from the earlier era. If some com-

\footnotetext{
${ }^{12}$ The 3 May 1999 Oklahoma City area tornado produced 38 direct fatalities and $\$ 1$ billion in damage. Based on its relation to the "After Flint" regression line, approximately 700 fatalities would have occurred in the "Flint and before" era.
}

ponent of the IWS breaks down, as when events are poorly forecast (as some events inevitably will be), dissemination is inadequate, or when community preparedness is poor, then the results can be comparable to the era before the inception of public tornado forecasting.

It is likely that the downward trends in casualties we have shown must begin to level off at some point. Tornadoes are virtually certain to cause some fatalities, no matter what preparations are made and no matter how accurately we can forecast them. There can be little doubt that advances in science and technology have helped maintain the downward trend in fatalities. Moreover, the increasing dispersion of the slowly growing national population is perhaps increasing the population at risk, on the whole.

However, storm spotting is going to be an important component of an integrated warning system in any foreseeable future. The radar horizon problem alone will limit the ranges at which tornadoes can be detected by any current radar, for instance. Spotters can help compensate for this physical limitation associated with any radar. As we have tried to show, the integrated warning system, whatever its imperfections, has been successful in reducing tornado casualties. Small, relatively weak events almost certainly will continue to evade detection at times. Even tornadoes of modest intensity can result in casualties under some circumstances. Large, violent events are likely to produce at least some casualties 
when they strike populated areas, no matter how accurate and effective the watches and warnings become.

Increasingly, tornado fatalities are related to bad luck, where actions that normally would suffice to save lives are not sufficient (as in the Jarrell, Texas, event of 27 May 199713), or where life-saving actions are precluded by circumstances. Moreover, there almost certainly will be some isolated events that will slip by undetected and create casualties, such as the tornado near Gainesville, Georgia, on 27 March 1998. The current low average annual death toll certainly is no accident, but as the preliminary casualty figures already in for 1998 show, the reduced fatality rates should not be used as an argument that the tornado problem has been "solved." The year 1998 has seen more than 130 fatalities, which by recent standards is a very large death toll. To some extent, this has been associated with bad luck (strong and violent tornadoes hitting communities with marginal construction, such as mobile home parks, often at night) but the year could have been worse: as noted, no major population center has been hit directly by a violent tornado. Failing to acknowledge the continuing threat from tornadoes could make us victims of our own success; our society remains vulnerable to tornadoes, as the annual damage figures and the occasional events of bad luck show. Maintaining a low fatality rate will not be possible if commitments to all the components of an IWS are not maintained. Clearly, further reductions in the casualty rate will require even greater investments than at present.

It is not difficult to imagine situations that could result in large fatality totals from a single event in the future. For example, imagine a violent tornado hitting a crowded sports facility during a sporting event, or a packed amusement park on a Saturday afternoon (a situation narrowly missed on 13 June 1998 in Oklahoma City, Oklahoma), or a tornado following a path down gridlocked intracity freeways during rush hour. No matter how effective the watches and warnings are in such a case, it is likely that major casualty figures would result. The record shows a tendency for considerable interannual variability about the overall trend owing to both good and bad luck. Recently, the nation has been relatively fortunate; no major population centers (on the order of St. Louis, Dallas, Atlanta, or Chicago) have been hit hard in the last 30 years. For instance, if the devastating tornado on 8 April 1998 had hit Birmingham, Alabama, directly the casualty figures could have been substantially higher than they were. The tornado

\footnotetext{
${ }^{13}$ In this event, where several homes without basements were swept completely off their foundations, taking shelter in an interior room was inadequate protection. Although safety rules make it clear that below-ground shelters are preferred, interior rooms are normally adequate for all but the most violent tornadoes. Inevitably, a few unlucky people taking shelter in interior rooms will become casualties in unusually damaging tornado events.
}

that hit Nasheville, Kentucky, on 16 April 1998 was not a violent one. We cannot expect such luck to continue indefinitely; it is not a matter of if a population center is struck hard, it is only a matter of when one will be struck.

We believe there is no choice, therefore, but to maintain vigilance and continue to put resources toward trying to avert such disasters to the best of our collective ability. The public has come to expect public weather services to provide timely, accurate forecasts of such events and may have an exaggerated expectation of our ability to do so. Moreover, dissemination of warnings continues to be a weak link in an IWS. For example, in spite of excellent watches and warnings during the recent Florida outbreak of tornadoes on 22-23 February 1998, the 42 fatalities in this outbreak illustrate several potential problems: the difficulty of tornadoes late at night, poor public preparedness, large mobile home and recreational vehicle parks offering virtually no shelter from tornadoes, etc. The fatality trend can be driven lower than it is now, but it will take considerable additional effort and spotters need to be part of that effort.

Further, public awareness should include public acceptance of at least some part of the responsibility for their own safety. The downward trend after 1925 suggests that at the time, the acceptance of this responsibility was reasonably well understood. For instance, tornado cellars for home in rural areas once were widespread; they are increasingly rare today. Currently, many people believe that it is mainly the public weather services that bear the lion's share of the responsibility for public safety in the event of severe weather. This attitude needs to be revised. By no means do we want to diminish the importance of the NWS in an integrated warning system, but for the system to work properly, all its members must take on their share of the responsibility. There is not likely ever to be a time when tornadoes can be forecast with pinpoint accuracy in space and time, and it is quite likely that important events will be missed even as we are improving our ability to provide accurate watches and warnings. The state of meteorological science with respect to tornadoes has improved greatly but is still far from a level of understanding that could prevent all false alarms and failures to detect. If the public is to be spared as many casualties as possible, part of our message must be to encourage the users of hazardous weather information to develop plans for how to deal with the occasional events that are poorly anticipated, and how to account for the finite capabilities of weather forecasters to deal with tornadoes. Spotters are now and will continue to be an important part of those plans.

Tornadoes are rare events, and it is possible to spend an entire lifetime, even in the center of what is known colloquially as "Tornado Alley," and never even see a tornado, much less experience one. Further, the average annual fatality count from tornadoes is no longer at a level where it regularly attracts much attention; only if 
the bad luck of 1998 continues is there much hope of continuing publicity about tornado vulnerability. Apathy and indifference can lead to disasters, especially on the margins of the tornado-prone parts of the United States. Many citizens in such locations may be unaware of the possibility of significant tornadoes, in spite of the historical record showing clearly that strong and violent tornadoes are possible anywhere over at least the eastern two-thirds of the nation. Complacency means an increased risk of disasters in those places where public perceptions are falsely on the side of "It can't happen here." Spotting networks and preparedness efforts (including public education and participation in severe weather awareness programs) can pay off in reducing risks, but it takes considerable effort to create and maintain vigilant spotter programs in locations where the public has a false sense of security about tornado risks. The spotters themselves may lose interest waiting to see what is, after all, a rare event.

The history of tornadoes shows pretty clearly that actions taken in preparation for tornadoes are often deferred until after a disaster has occurred. Our review of the history of the development of spotters suggests that the IWS has been shaped primarily by major events that produced numerous fatalities, like the Tri-State tornado, the so-called Woodward tornado of 9 April 1947, the disasters of 1953 (i.e., Waco, Texas, on 11 May; Flint, Michigan, on 8 June; and Worcester, Massachusetts, on 9 June), the 1965 Palm Sunday outbreak, the "Super Outbreak" of 1974, and so on. In effect, it seems that major disasters are needed for any progress to be made. Experience suggests that the memory of such disasters fades from the collective consciousness rather faster than it should. We believe that resource expenditures must be continued to maintain the sense of vigilance created by such events; otherwise, the tragic consequences will be repeated at another time and/or another place. The lessons learned will have to be relearned after new and unnecessary fatalities. Although most citizens will never experience a tornado, it is possible to control the fatality count with proper preparations, disaster plans, and an integrated warning system.

Acknowledgments. Tom Grazulis supplied part of the data used in this study, as well as some helpful discussions. Allen Pearson, Herb Lieb, Rainer Dombrowsky, Mike Redman, Gary Woodall, Mike Mogil, Bob Carnahan, Jim Purpura, and Dan Purcell all provided input that contributed substantially to the factual content of historical aspects in this review. We appreciate thoughtful and beneficial reviews from Don Burgess and an anonymous referee.

\section{REFERENCES}

AMS, 1955: Texas radar tornado warning network. Bull. Amer. Meteor. Soc., 36, 234.

__ 1957a: News and notes: Tornado film wins citation. Bull. Amer. Meteor. Soc., 38, 300.

_, 1957b: About our members. Bull. Amer. Meteor. Soc., 38, 410411.

Bates, F. C., 1962: Severe local storm forecasts and warnings and the general public. Bull. Amer. Meteor. Soc., 43, 288-291.

Corfidi, S. F., 1999: The birth and early years of the Storm Prediction Center. Wea. Forecasting, 14, 507-525.

Doswell, C. A., III, and D. W. Burgess, 1988: On some issues of United States tornado climatology. Mon. Wea Rev., 116, 495501.

Galway, J. G., 1985: J. P. Finley: The first severe storms forecaster (Part 1). Bull. Amer. Meteor. Soc., 66, 1389-1395.

_ 1989: The evolution of severe thunderstorm criteria within the Weather Bureau. Wea. Forecasting, 4, 585-592.

_ 1992: Early severe thunderstorm forecasting and research by the United States Weather Bureau. Wea. Forecasting, 7, 564587.

Grazulis, T. P., 1993: Significant Tornadoes 1680-1991. Environmental Films, 1326 pp.

Leik, R. K., T. M. Carter, and J. P. Clark, 1981: Community response to natural hazard warning. U.S. Dept. of Commerce, 77 pp. [NTIS PB82-111287.]

López, R. E., and R. L. Holle, 1998: Changes in the number of lightning deaths in the United States during the twentieth century. J. Climate, 11, 2070-2077.

Lynch, D., 1970: Tornado ... Texas Demon in the Wind. Texian Press, 163 pp.

Moller, A. R., and C. A. Doswell, 1988: A proposed advanced storm spotter's training program. Preprints, 15th Conf. Severe Local Storms, Baltimore, MD, Amer. Meteor. Soc., 173-177.

— M. P. Foster, and C. A. Doswell III, 1993: Some considerations of severe local storm product dissemination in the modernized and restructured NWS. Preprints, 17th Conf. Severe Local Storms, St. Louis, MO, Amer. Meteor. Soc., 375-379.

—, C. A. Doswell III, M. P. Foster, and G. R. Woodall, 1994: The operational recognition of supercell thunderstorm environments and storm structures. Wea. Forecasting, 9, 327-347.

NWS, 1988: The Saragosa, TX, tornado. Natural Disaster Survey Rep., National Weather Service, Southern Region Headquarters, Fort Worth, TX, 45 pp. [Available from Customer Service Core, National Weather Service, 1225 East-West Highway, Silver Spring, MD 20910.]

Ostby, F. P., 1992: Operations of the National Severe Storms Forecast Center. Wea. Forecasting, 7, 546-563.

Perry, R. W., and A. H. Mushkatel, 1984: Disaster Management. Quorum Books, 280 pp.

Popkin, R., 1967: The Environmental Science Services Administration. Frederick A. Praeger Publishers, 278 pp.

Reynolds, G. W., 1958: Venting and other building practices as practical means of reducing damage from tornado low pressures. Bull. Amer. Meteor. Soc., 39, 14-20.

Weather Bureau Survey Team, 1965: Report of Palm Sunday Tornadoes of 1965. U.S. Weather Bureau, 65 pp. [Available from Customer Service Core, National Weather Service, 1225 EastWest Highway, Silver Spring, MD 20910.]

Whitnah, D. R., 1961: A History of the United States Weather Bureau. University of Illinois, $267 \mathrm{pp}$. 